\title{
Challenges and Pitfalls of Using Repeat Spirometry Recordings in Routine Primary Care Data to Measure FEV, Decline in a COPD Population
}

\author{
Hannah R Whittaker ${ }^{\prime}$ \\ Steven J Kiddle $\mathbb{D}^{2}$ \\ Jennifer K Quint (D)
}

'National Heart and Lung Institute, Imperial College London, London, UK; ${ }^{2}$ MRC Biostatistics Unit, University of Cambridge, Cambridge, UK
Correspondence: Hannah R Whittaker Email h.whittaker@imperial.ac.uk
Background: Electronic healthcare records (EHR) are increasingly used in epidemiological studies but are often viewed as lacking quality compared to randomised control trials and prospective cohorts. Studies of patients with chronic obstructive pulmonary disease (COPD) often use the rate of forced expiratory volume in 1 second $\left(\mathrm{FEV}_{1}\right)$ decline as an outcome; however, its definition and robustness in EHR have not been investigated. We aimed to investigate how the rate of $\mathrm{FEV}_{1}$ decline differs by the criteria used in an EHR database.

Methods: Clinical Practice Research Datalink and Hospital Episode Statistics were used. Patient populations were defined using 8 sets of criteria around repeated $\mathrm{FEV}_{1}$ measurements. At a minimum, patients had a diagnosis of COPD, were $\geq 35$ years old, were current or ex-smokers, and had data recorded from 2004. $\mathrm{FEV}_{1}$ measurements recorded during follow-up were identified. Thereafter, eight populations were defined based on criteria around: i) the exclusion of patients or individual measurements with potential measurement error; ii) minimum number of $\mathrm{FEV}_{1}$ measurements; iii) minimum time interval between measurements; iv) specific timing of measurements; v) minimum follow-up time; and vi) the use of linked data. For each population, the rate of $\mathrm{FEV}_{1}$ decline was estimated using mixed linear regression.

Results: For $7 / 8$ patient populations, rates of $\mathrm{FEV}_{1}$ decline (age and sex adjusted) were similar and ranged from $-18.7 \mathrm{~mL} /$ year $(95 \% \mathrm{CI}-19.2$ to -18.2$)$ to $-16.5 \mathrm{~mL} /$ year $(95 \% \mathrm{CI}$ -17.3 to -15.7$)$. Rates of $\mathrm{FEV}_{1}$ decline in populations that excluded patients with potential measurement error ranged from $-79.4 \mathrm{~mL} /$ year $(95 \% \mathrm{CI}-80.7$ to -78.2$)$ to $-46.8 \mathrm{~mL} /$ year (95\% CI -47.6 to -46.0$)$.

Conclusion: $\mathrm{FEV}_{1}$ decline remained similar in a COPD population regardless of number of $\mathrm{FEV}_{1}$ measurements, time intervals between measurements, follow-up period, exclusion of specific $\mathrm{FEV}_{1}$ measurements, and linkage to HES. However, exclusion of individuals with questionable data led to selection bias and faster rates of decline.

Keywords: electronic healthcare records, spirometry, COPD, lung function

\section{Introduction}

Electronic health care record (EHR) databases consist of data routinely collected as part of clinical care and are often used for healthcare research. Whilst EHR databases have many strengths, one concern is that data are not collected for the purpose of research and that when tests are undertaken, they are not done so at routine intervals as they would be in arandomised control trial (RCT), nor is the reason for a test being undertaken at that specific point in time always known. ${ }^{1}$ 
EHR databases differ from RCTs or prospective cohort studies, which have structured data collection where data are collected at specific times for research purposes, by specific healthcare technicians, with specific equipment following specific protocols. EHRs are becoming increasingly used in epidemiological research; however, they are often viewed as lacking quality.

In studies of people with chronic obstructive pulmonary disease (COPD), longitudinal spirometry measurements, such as forced expiratory volume in 1 second $\left(\mathrm{FEV}_{1}\right)$, are often used to estimate lung function decline, a common marker of disease progression. ${ }^{2}$ Lung function decline is important as it is associated with quality of life, symptom burden, and mortality., ${ }^{3,4}$ Unlike RCTs and cohort studies, the sporadic nature of lung function measurements recorded in EHR can lead to greater apparent variation in lung function in COPD patients. This could be due to measurement error, the number of measurements over follow-up, time intervals between measurements, follow-up time, and the reason or time at which lung function measures are recorded by healthcare practitioners.

The Clinical Practice Research Datalink (CPRD) is a routinely collected EHR database of general practices in the UK and contains clinical patient information that is recorded at general practices during consultations. In this setting, spirometry measurements in COPD patients are performed by healthcare practitioners during visits to the general practice. The quality and outcomes framework (QOF) for COPD incentivises healthcare practitioners in general practice to perform spirometry every 15 months in COPD patients. ${ }^{5}$ A previous validation study of spirometry recordings in CPRD found that more than $96 \%$ of recordings had adequate quality whereby a valid interpretation could be made by a respiratory physician. ${ }^{6}$ Despite this, it is possible that other factors, such as timings of measurements, time intervals, and follow-up time, could lead to differences in longitudinal changes in lung function decline.

We aimed to investigate the rate of $\mathrm{FEV}_{1}$ decline and how variation in $\mathrm{FEV}_{1}$ differs by the criteria used to define the rate of $\mathrm{FEV}_{1}$ decline in CPRD, a routinely collected database. Specifically, we aimed to investigate how criteria around measurement error, the number of $\mathrm{FEV}_{1}$ measurements, timing of measurements, follow-up time, and use of additional linked databases may lead to differences in $\mathrm{FEV}_{1}$ decline estimates using CPRD. With the evergrowing use of EHR data for cohort studies and pragmatic trials, it is important to understand how robust EHR derived lung function decline is as an outcome.

\section{Methods}

\section{Patient Eligibility Criteria}

CPRD-GOLD (GOLD database of CPRD) was used and linked to a secondary care database, Hospital Episode Statistics (HES). CPRD contains clinical information on patients recorded at the general practices, such as diagnoses, prescriptions, consultation information, referrals, and tests performed (e.g., spirometry). HES contains information on secondary care processes for patients registered at general practices in England who are eligible for linkage with CPRD. In this study, COPD patients were identified using a validation definition of COPD in CPRD. ${ }^{7}$ COPD patients were identified if they had a clinical diagnosis of COPD, were over 35 years of age, and were smokers or ex-smokers. The start of follow-up (index date) was the first $\mathrm{FEV}_{1}$ measurement date after the following criteria were met: i) COPD diagnosis; ii) date of registration with current general practice; iii) date at which data recorded at a general practice were deemed to be of research quality ("up-tostandard"); iv) date at age 35; and v) after the implementation of QOF from the 1st January 2004. End of follow-up was the first date of the following: i) death date; ii) date at which the patient transferred to a non-CPRD GP; or iii) the 31st December 2017. Figure 1 describes the study design used to create this base population.

\section{FEV , Measurements}

$\mathrm{FEV}_{1}$ measurements recorded between the index date and the end of follow-up were identified. FEV $_{1}$ measurements were recorded in millilitres. Measurements recorded in litres were transformed to $\mathrm{mL}$ and measurements that were higher than 7 litres were excluded $(94.8 \%$ of all measurements over follow-up were below 7 litres). A cut off $7 \mathrm{~L}$ was used based on the average total lung capacity for a healthy adult male. Whilst an $\mathrm{FEV}_{1}$ measurement of $7 \mathrm{~L}$ would be considered high in COPD patients, a distribution of $\mathrm{FEV}_{1}$ measurements was considered based off previous studies. ${ }^{8-10}$ A previous validation study of spirometry in CPRD GOLD found that of $96.5 \%$ of spirometry traces recorded at the general practice in COPD patients were of adequate quality where a respiratory clinician was able to make an interpretation. ${ }^{6}$ Of these, $27.9 \%$ were identified as post-bronchodilator $\mathrm{FEV}_{1}, 7.2 \%$ were confirmed to be pre-bronchodilator $\mathrm{FEV}_{1}$, and for the remaining measurements it was unclear if the measurements were pre- or post-bronchodilator. 


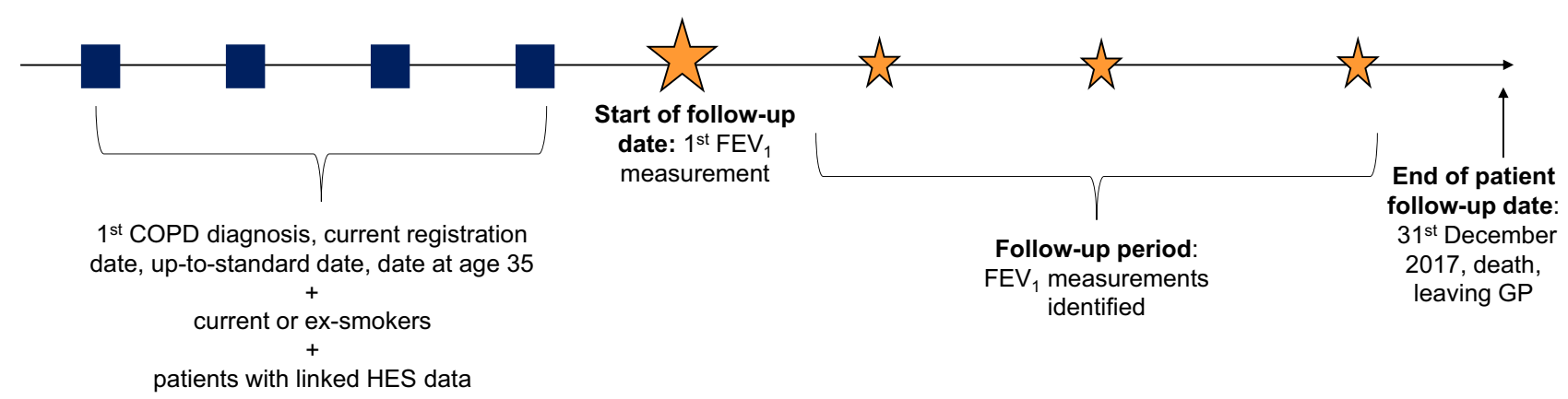

Figure I Study design.

\section{Patient Populations}

In order to understand how the rate of $\mathrm{FEV}_{1}$ declines and its variation differs based on the criteria used to define longitudinal $\mathrm{FEV}_{1}$ decline, the following patient populations were created using specific criteria:

1. patients with at least two $\mathrm{FEV}_{1}$ measurements at least six months apart (base population). A minimum period of six months was chosen in order to estimate medium-term lung function decline;

2. patients in the base population excluding those who had an $\mathrm{FEV}_{1}$ greater than $10 \%, 20 \%$, and $30 \%$ of their previous and subsequent $\mathrm{FEV}_{1}$ measurement. These measurements were regarded as potential measurement error, and patients were hence excluded;

3. patients in the base population excluding individual $\mathrm{FEV}_{1}$ measurements that were greater than $10 \%, 20 \%$, and $30 \%$ of the previous and subsequent $\mathrm{FEV}_{1}$ measurement. These measurements were regarded as potential measurement error and were hence excluded;

4. patients in the base population excluding measurements that were within one week of an exacerbation of COPD (AECOPD) because AECOPD events are associated with decreased $\mathrm{FEV}_{1}$ both before and after an AECOPD; ${ }^{11}$

5. patients with at least three or four $\mathrm{FEV}_{1}$ measurements, rather than two, of which at least two were at least six months apart (with no other time constraint on the other measurements). At least three and four measurements were chosen following a common number of measurements used in RCT and cohort studies;
6. patients with at least two $\mathrm{FEV}_{1}$ measurements with at least six months or 1-year time intervals between all measurements. This was chosen following the nature of RCTs and cohort studies whereby spirometry measurements are recorded at regular intervals;

7. patients in the base population with at least three years of follow-up following the maximum length of previous RCTs on lung function decline in COPD patients; ${ }^{12}$

8. patients in the base population and patients meeting inclusion criteria but who did require HES linkage eligibility. Approximately $60 \%$ of CPRD-GOLD patients are eligible for HES linkage, which can restrict populations.

Figure 2 illustrates how each patient population was identified using spirometry measurements.

\section{Statistical Analysis}

Baseline patient characteristics were described for all patient populations using means (standard deviation [SD]), medians (interquartile range [IQR]), and proportions (\%). Baseline characteristics included age, gender, the closest recorded smoking status (smokers or ex-smokers) to index date, the closest BMI (underweight, normal, overweight, obese using standard categories) and modified MRC dyspnoea (0-4) recorded three years prior or two years after index date, severity of obstruction using $\mathrm{FEV}_{1 \%}$ predicted $\left(\mathrm{FEV}_{1}>80 \%\right.$ predicted, $\mathrm{FEV}_{1} 50-80 \%$ predicted, $\mathrm{FEV}_{1} 30-50 \%$ predicted, and $\mathrm{FEV}_{1}<30 \%$ predicted calculated using patient's first $\mathrm{FEV}_{1}$ measurement, height, and gender ${ }^{13}$ ), and AECOPD frequency 
1
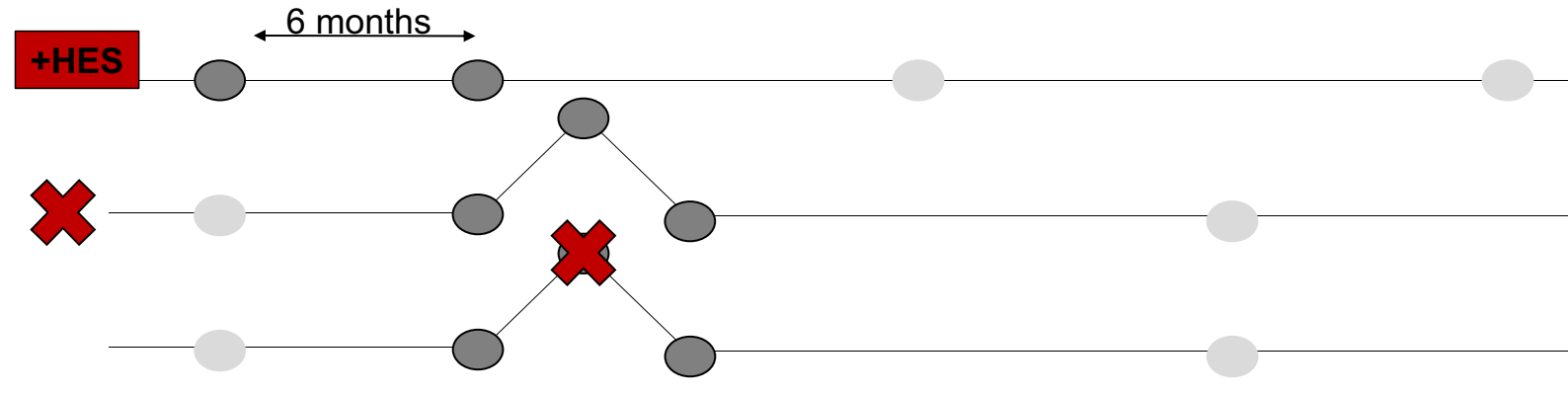

4

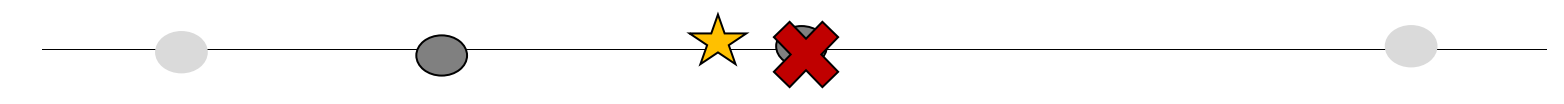

5

6

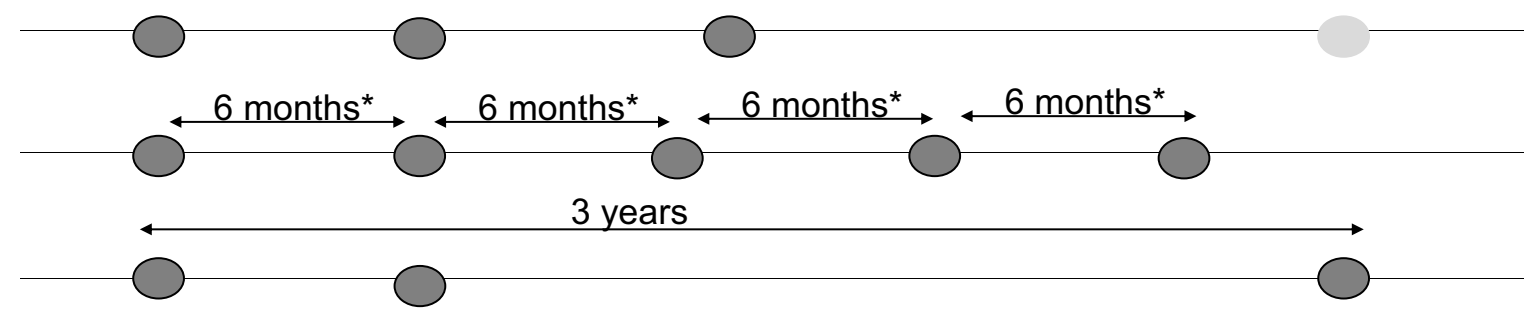

7

4

8

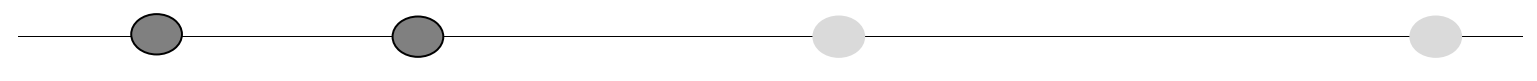

Figure 2 Patient populations.

Notes: Patients with at least $2 \mathrm{FEV}$, measurements at least 6 months apart with linked HES data; 2: Excluding patients with an FEV , greater than $10 \%$, 20\%, or $30 \%$ of the previous $\mathrm{FEV}_{1}$; 3) Excluding measurements that are greater than 10,20 , 0r $30 \%$ of the previous $\mathrm{FEV}_{1}$ and subsequent $\mathrm{FEV}$; 4) Excluding measurements that are within I week of an AECOPD; 5) At least 3 (or 4) FEV , measurements with at least 2 at least 6 months apart; 6 ) FEV, measurements that are all at least 6 months (*or I year) apart; 7) At least 3 years of follow-up with at least 2 FEV, measurements at least 6 months apart; 8) At least 2 FEV, measurements at least 6 months apart (regardless of linked HES data).

and severity (none, 1 moderate and 0 severe, 2 moderate and 0 severe, $\geq 3$ moderate and 0 severe, 1 severe and any moderate, and $\geq 2$ severe and any moderate) in the year prior to index date. Moderate AECOPD were defined as GP treated AECOPD and severe AECOPD were defined as hospitalised AECOPD. In addition, the median number of $\mathrm{FEV}_{1}$ measurements (IQR and minimum/maximum number) and follow-up time were described for each population.

Mixed linear regression was used to estimate the rate of $\mathrm{FEV}_{1}$ decline in $\mathrm{mL} /$ year. Random effects included both random intercepts and random slopes allowing the intercept and rate of decline to vary by patients. Models included a non-adjusted crude model, a minimally adjusted model adjusted for age and gender, a non-adjusted crude model for patients with complete baseline covariates, and a fully adjusted model adjusted for age, gender, smoking status, BMI, mMRC, $\mathrm{FEV}_{1} \%$ predicted, and AECOPD frequency. Within patient variation in $\mathrm{FEV}_{1}(\mathrm{~mL})$ was estimated from mixed linear models.

In addition, a ninth analysis population was used to describe the rate of $\mathrm{FEV}_{1}$ decline using linear regression rather than mixed linear regression to understand how clustering at the patient level influences the rate of $\mathrm{FEV}_{1}$ decline in the base population (population 1). Linear regression models included an unadjusted model, a minimally adjusted model, an unadjusted model for patients with complete baseline covariates, and a fully adjusted model adjusted for the same covariates as those used in the mixed linear regression model. Similarly, RCTs commonly use a baseline $\mathrm{FEV}_{1}$ measurement and a follow-up measurement to describe the change in $\mathrm{FEV}_{1}$ over time. This method was used to compare the rates of decline against those estimated using linear regression and mixed linear regression methods. This was calculated using patient's first and last $\mathrm{FEV}_{1}$ over follow-up divided by the time between these two measurements (in years) to estimate rate of $\mathrm{FEV}_{1}$ decline in $\mathrm{mL} / \mathrm{year}$.

\section{Results}

The numbers of patients included in each population varied because of the different criteria for repeated $\mathrm{FEV}_{1}$ measurements. Population eight included the greatest 
number of patients $(\mathrm{N}=125,682)$ as it did not require linked HES data and population two included the fewest number of patients because patients were excluded if they had an $\mathrm{FEV}_{1}$ that was greater than $10 \%$ of their previous and subsequent $\mathrm{FEV}_{1}(\mathrm{~N}=29,058)$. Table 1 summarises baseline characteristics for all populations. Populations were similar in terms of age, gender, smoking status, BMI, mMRC, and AECOPD frequency. However, population two included fewer severely obstructed patients and more mild COPD patients (i.e., $\mathrm{FEV}_{1}>80 \%$ predicted).

Most populations had a median of $4 \mathrm{FEV}_{1}$ measurements during follow-up; however, patients in population two (that excluded patients with an $\mathrm{FEV}_{1}$ greater than $10 \%$ or $20 \%$ of the previous and subsequent $\mathrm{FEV}_{1}$ measurements) had fewer $\mathrm{FEV}_{1}$ measurements over follow-up with a median of 3 . On the other hand, population five that included patients with at least $4 \mathrm{FEV}_{1}$ measurements had a median of 6 measurements over follow-up. In addition, for population one, the median $\mathrm{FEV}_{1}$ measurement over follow-up was 1.5 L (IQR 1.08-2.03 (Supplementary Figure E1).

\section{Rate of FEV, Decline}

Minimally adjusted and fully adjusted mean rates of $\mathrm{FEV}_{1}$ decline in each population are shown in Figures 3 and 4. Estimates from crude analyses can be found in the supplementary material (Tables E1-E9). Mean rates of $\mathrm{FEV}_{1}$ decline were similar in all patient populations except for population two (i.e., exclusion of patients with $\mathrm{FEV}_{1}$ greater than a) $10 \%$, b) $20 \%$, and c) $30 \%$ of the previous and subsequent $\mathrm{FEV}_{1}$ measurements. Minimally adjusted rates of $\mathrm{FEV}_{1}$ decline in population one and three-eight ranged from $-18.7 \mathrm{~mL} /$ year $(95 \% \mathrm{CI}-19.2$ to -18.2$)$ to $-16.5 \mathrm{~mL} /$ year $(95 \% \mathrm{CI}-17.3$ to -15.7$)$. The mean rates of $\mathrm{FEV}_{1}$ decline for population two was $-79.4 \mathrm{~mL} /$ year $(95 \%$ $\mathrm{CI}-80.7$ to -78.2 ) excluding those with an $\mathrm{FEV}_{1}$ greater than $10 \%$ of their previous $\mathrm{FEV}_{1},-57.1 \mathrm{~mL} /$ year $(95 \% \mathrm{CI}$ -58.0 to -56.2 ) excluding patients with an $\mathrm{FEV}_{1}$ greater than $20 \%$ of their previous $\mathrm{FEV}_{1}$, and $-46.8 \mathrm{~mL} /$ year $(95 \%$ $\mathrm{CI}-47.6$ to -46.0 ) excluding patients with an $\mathrm{FEV}_{1}$ greater than $30 \%$ of their previous $\mathrm{FEV}_{1}$.

Fully adjusted rates of $\mathrm{FEV}_{1}$ decline in population one and three-eight ranged from $-14.6 \mathrm{~mL} /$ year $(95 \% \mathrm{CI}-15.7$ to -13.6$)$ to $-9.8 \mathrm{~mL} /$ year $(95 \% \mathrm{CI}-11.5$ to -8.1$)$. Fully adjusted mean rates of $\mathrm{FEV}_{1}$ decline for population two were $-94.9 \mathrm{~mL} /$ year $(95 \% \mathrm{CI}-97.5$ to -92.3$)$ excluding those with an $\mathrm{FEV}_{1}$ greater than $10 \%$ of their previous $\mathrm{FEV}_{1},-64.3 \mathrm{~mL} /$ year $(95 \% \mathrm{CI}-66.1$ to -62.5$)$ excluding those with an $\mathrm{FEV}_{1}$ greater than $20 \%$ of their previous $\mathrm{FEV}_{1}$, and $-51.4 \mathrm{~mL} /$ year $(95 \% \mathrm{CI}-53.0$ to -49.8$)$ excluding those with an $\mathrm{FEV}_{1}$ greater than $30 \%$ of their previous $\mathrm{FEV}_{1}$.

It is important to note that minimally adjusted and fully adjusted models differed by patient numbers due to complete case analysis. Tables E1-E8 provide further information on unadjusted models, minimally adjusted models, unadjusted models in patients with complete data, and fully adjusted models. Unadjusted models in patients with complete baseline covariates were similar to fully adjusted models. Fully adjusted complete case analyses included fewer patients due to missing BMI, mMRC, and height (used to calculate $\mathrm{FEV}_{1} \%$ predicted).

Estimates using linear regression models were similar for unadjusted and minimally adjusted analyses; however, the rate of $\mathrm{FEV}_{1}$ decline was faster in fully adjusted analyses compared to rates estimated using mixed linear regression models (Table E9). The rate of $\mathrm{FEV}_{1}$ decline was also assessed in the base population (population 1) using patients first and last $\mathrm{FEV}_{1}$ measurements only. Overall, the mean unadjusted rate of $\mathrm{FEV}_{1}$ decline using this method was $-16.4 \mathrm{~mL} /$ year (SD 246.5).

Within patient variation of $\mathrm{FEV}_{1}$ in minimally adjusted mixed linear models ranged from $330.6 \mathrm{~mL}$ to $339.8 \mathrm{~mL}$ in populations one, four, five, seven, and eight. Within patient variation in $\mathrm{FEV}_{1}$ was slightly higher in population six at $350.7 \mathrm{~mL}$. Population two had the lowest within patient variation in $\mathrm{FEV}_{1}$ at $195.5 \mathrm{~mL}, 191.2 \mathrm{~mL}$, and $202.5 \mathrm{~mL}$ after excluding patients with an $\mathrm{FEV}_{1}$ greater than $10 \%, 20 \%$, and $30 \%$ of the previous $\mathrm{FEV}_{1}$ measurements, respectively. See Supplementary Tables E1-E8 for further details on within patient variation in all models and populations.

\section{Discussion}

This piece of work set out to describe potential differences in patient characteristics, $\mathrm{FEV}_{1}$ variability and rates of $\mathrm{FEV}_{1}$ decline between COPD populations defined using different requirements around $\mathrm{FEV}_{1}$ measurements in routinely collected data using CPRD. Specifically, how different definitions around measurement error, number of measurements, time intervals between measurements, follow-up time, and secondary care data linkage can lead to the selection of potentially different study populations. Overall, we found that regardless of the number of $\mathrm{FEV}_{1}$ measurements, time intervals between measurements, follow-up time, and secondary care data linkage, patient 


\begin{tabular}{|c|c|c|c|c|c|c|c|c|c|c|}
\hline 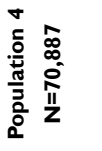 & $\begin{array}{l}\bar{p} \\
\tilde{w}\end{array}$ & $\begin{array}{l}\hat{E} \\
\stackrel{0}{ٍ} \\
\text { î } \\
0\end{array}$ & 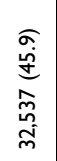 & 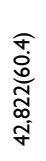 & 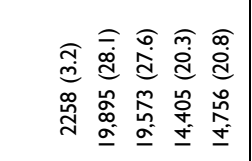 & 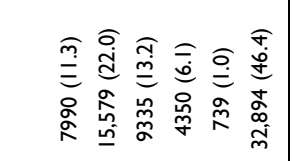 & 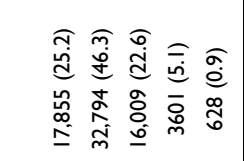 & 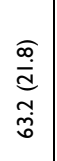 & 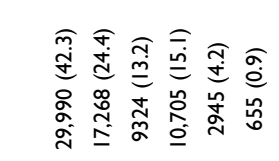 & 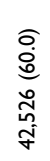 \\
\hline 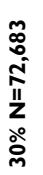 & $\underset{\substack{\mathfrak{y} \\
\tilde{m}}}{ }$ & 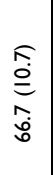 & 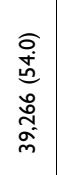 & 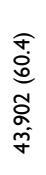 & 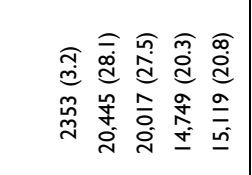 & 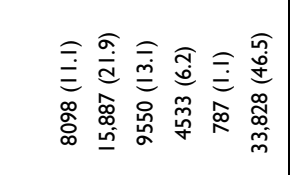 & 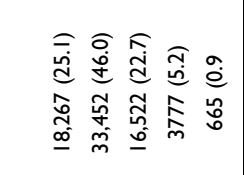 & $\frac{\widehat{\sigma}}{\frac{\hat{d}}{\mathrm{M}}}$ & 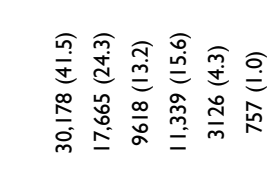 & 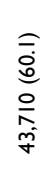 \\
\hline 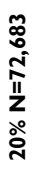 & 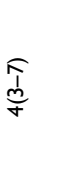 & 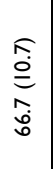 & 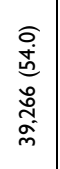 & 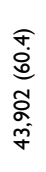 & 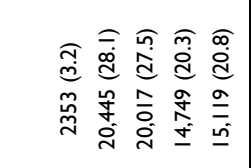 & 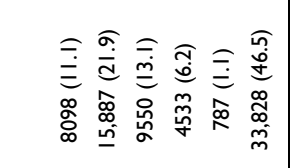 & 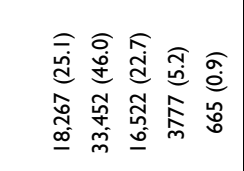 & 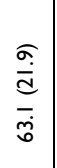 & 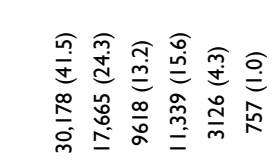 & $\begin{array}{l}\widehat{\overline{0}} \\
0 \\
\frac{0}{\wedge} \\
\text { 字 }\end{array}$ \\
\hline 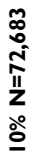 & $\begin{array}{l}\underset{1}{q} \\
\text { q } \\
\end{array}$ & $\begin{array}{l}\hat{R} \\
\stackrel{R}{O} \\
\stackrel{0}{0} \\
0\end{array}$ & 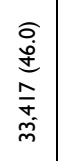 & 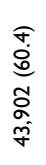 & 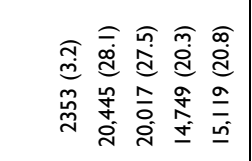 & 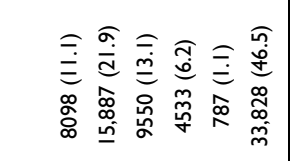 & 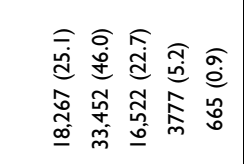 & $\frac{\frac{\sigma}{d}}{\frac{\hat{d}}{\dot{d}}}$ & 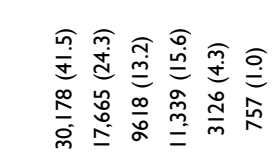 & 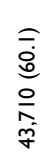 \\
\hline 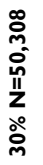 & 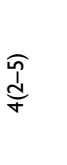 & 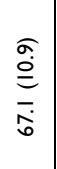 & 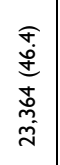 & 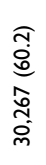 & 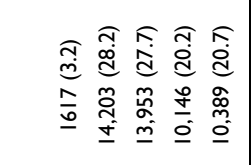 & 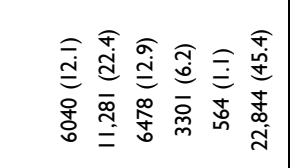 & 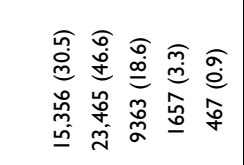 & $\begin{array}{l}\frac{\pi}{i} \\
\stackrel{0}{0} \\
0\end{array}$ & 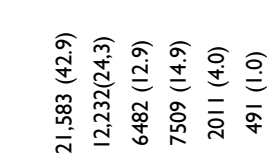 & $\begin{array}{l}\sigma \\
0 \\
0 \\
0 \\
0 \\
0 \\
\text { ते }\end{array}$ \\
\hline 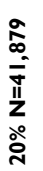 & 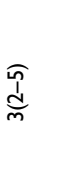 & 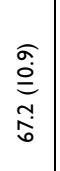 & 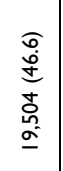 & 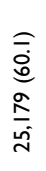 & 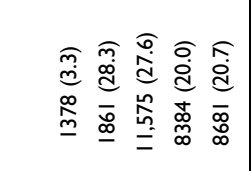 & 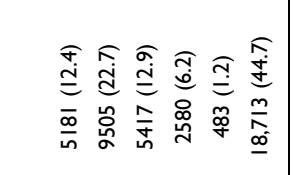 & 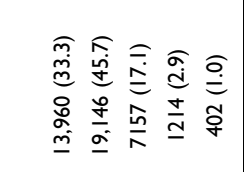 & 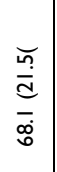 & 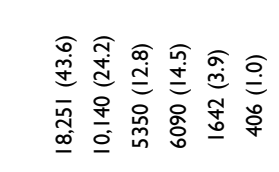 & 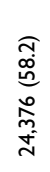 \\
\hline 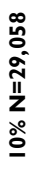 & 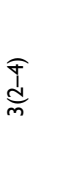 & 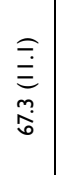 & 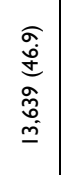 & 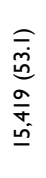 & 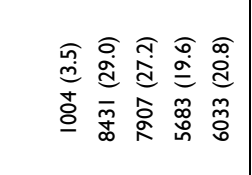 & 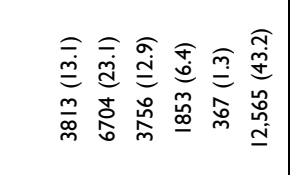 & 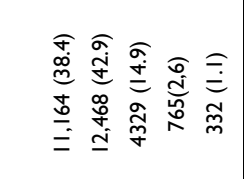 & 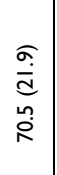 & 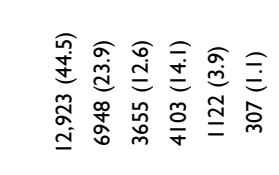 & 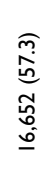 \\
\hline 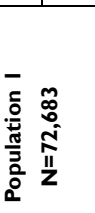 & $\begin{array}{l}\text { 禾 } \\
\hat{y}\end{array}$ & 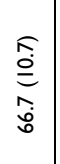 & 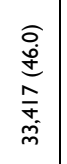 & 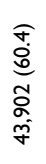 & 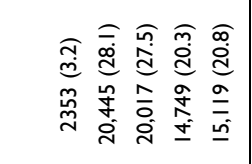 & 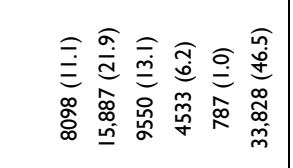 & 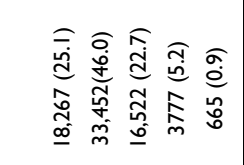 & $\frac{\widehat{\sigma}}{\frac{\hat{d}}{\mathrm{M}}}$ & 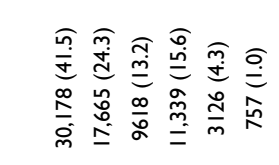 & 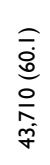 \\
\hline & 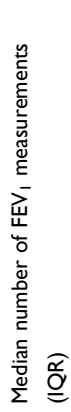 & $\begin{array}{l}8 \\
\underset{8}{8}\end{array}$ & 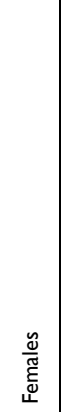 & 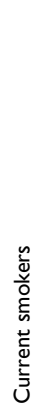 & 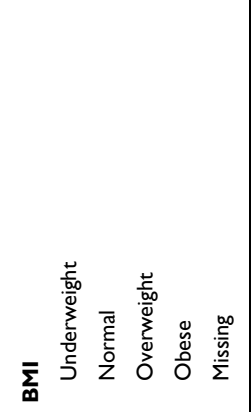 & $\sum_{\varepsilon}^{U}$ & 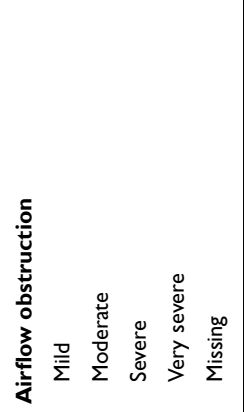 & 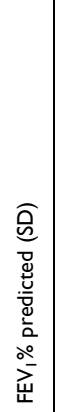 & 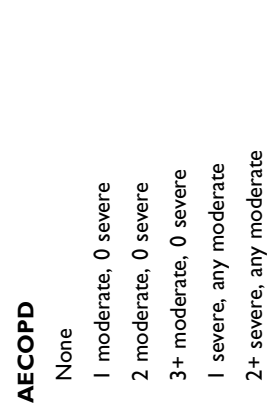 & 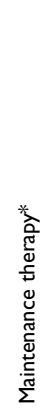 \\
\hline
\end{tabular}




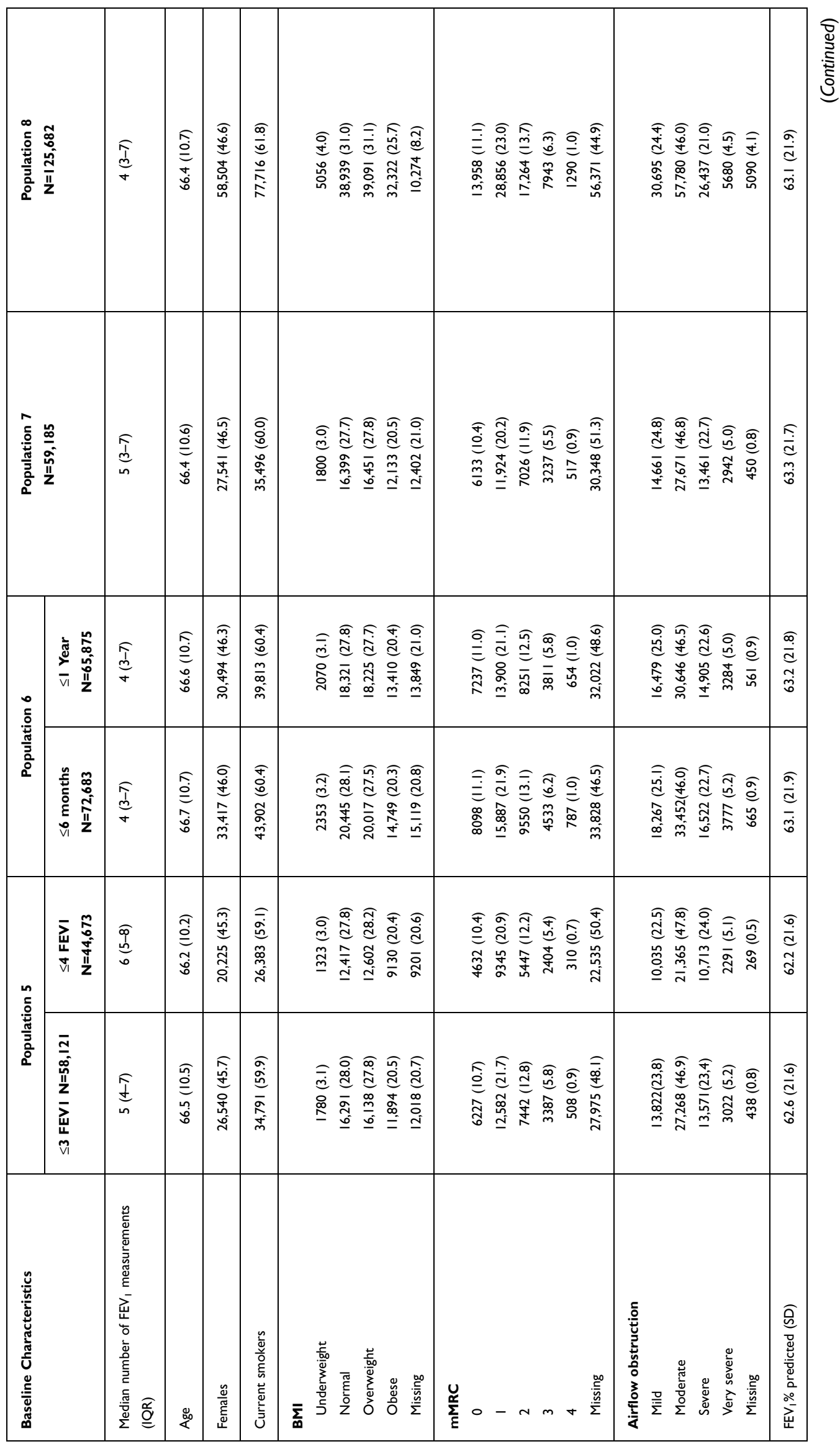




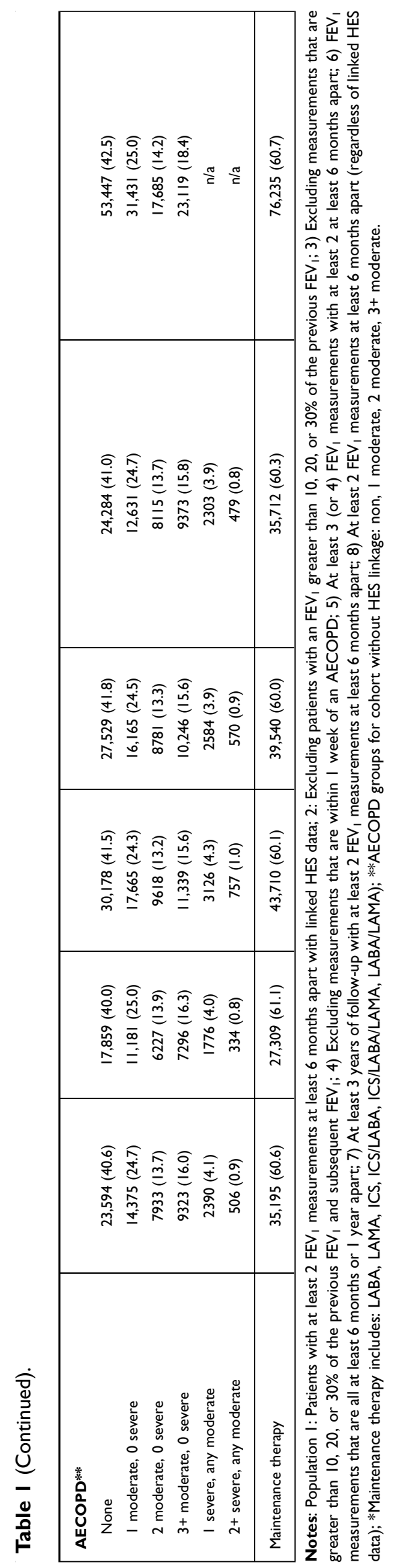

demographics, within patient $\mathrm{FEV}_{1}$ variability, and rates of $\mathrm{FEV}_{1}$ decline remained consistent. Similarly, results were consistent in populations that excluded individual $\mathrm{FEV}_{1}$ measurements that were likely due to measurement error. However, excluding patients (rather than individual measurements) with likely measurement error led to the exclusion of a specific group of COPD patients; severely obstructed patients (low $\mathrm{FEV}_{1 \%}$ predicted). This could lead to selection bias in studies that aim to use a representative population of COPD patients. In addition, using mixed linear regression provided estimates that were different from those using linear regression, suggesting that clustering at the patient level is important when investigating the rate of $\mathrm{FEV}_{1}$ decline in routinely collected data.

The mean annual rates of $\mathrm{FEV}_{1}$ decline described in this study for populations one and three to eight were similar to those reported in previous studies of COPD patients. $^{4,8,9}$ Interestingly, population two (those who were excluded due to potential measurement error) had faster rates of $\mathrm{FEV}_{1}$ decline. More patients with low $\mathrm{FEV}_{1}$ $\%$ predicted were excluded in this population, which meant that there were more patients with milder COPD (higher $\mathrm{FEV}_{1} \%$ predicted) than all other populations. Previous studies have suggested that rates of $\mathrm{FEV}_{1}$ decline are faster in COPD patients with milder disease because they have more absolute lung function to lose at baseline than those with severe disease. ${ }^{14}$ This also suggests that patients with lower $\mathrm{FEV}_{1} \%$ predicted are more likely to have poorly recorded spirometry (potential measurement error). It is possible that patients with more severe disease, and lower $\mathrm{FEV}_{1} \%$ predicted, were more likely to perform poor spirometry, which might have contributed to the high variation seen in this group of patients. Whilst the best of three spirometry recordings should be recorded by healthcare practitioners, it is possible that only one spirometry is performed and recorded if patients are too severe to perform three in a row. It is also important to note that the increase in $\mathrm{FEV}_{1}$ by $10 \%, 20 \%$, and $30 \%$ could be due to initiation of COPD medications, which can have an acute bronchodilation effect; however, studies have shown that this effect decreases over time in COPD patients on longterm treatment. ${ }^{15,16}$ Therefore, researchers should consider their research question prior to defining the rate of $\mathrm{FEV}_{1}$ decline.

It is also important to note that fewer patients were included in models with patients who had complete baseline covariate data. In CPRD-GOLD this is due to the lack 


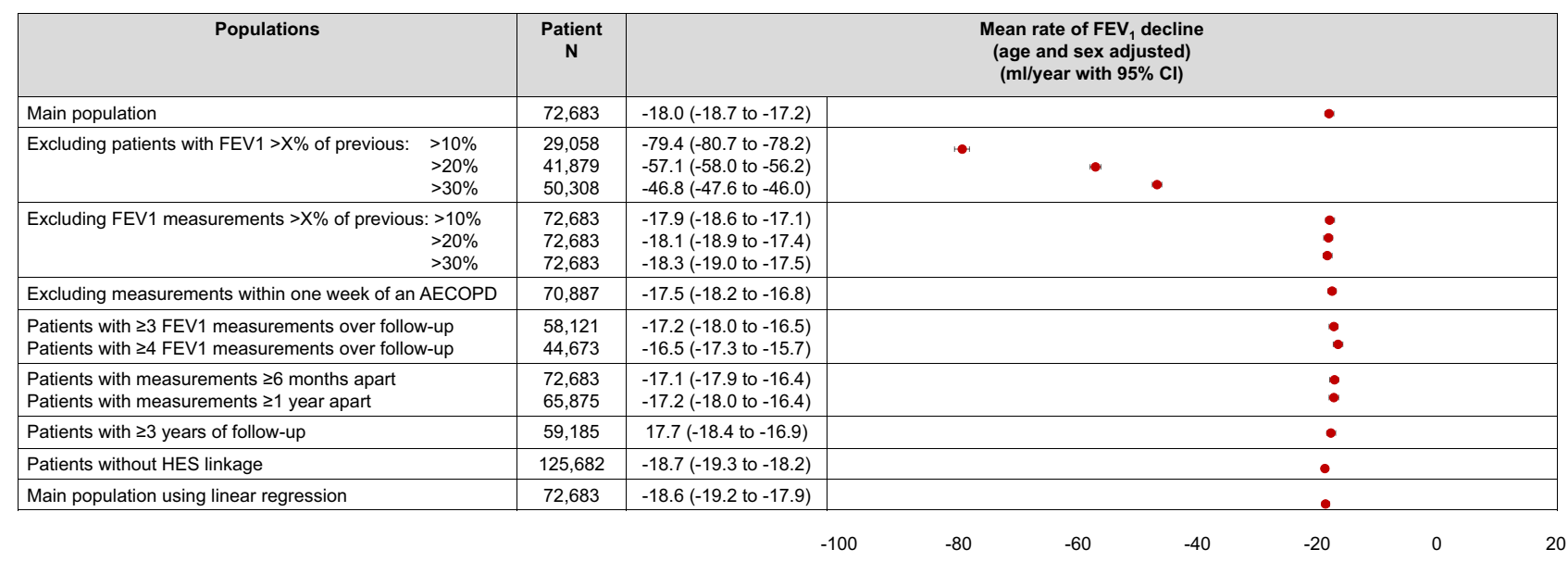

Figure 3 Minimally adjusted rates of FEV, decline.

Note: Adjusted for age and sex.

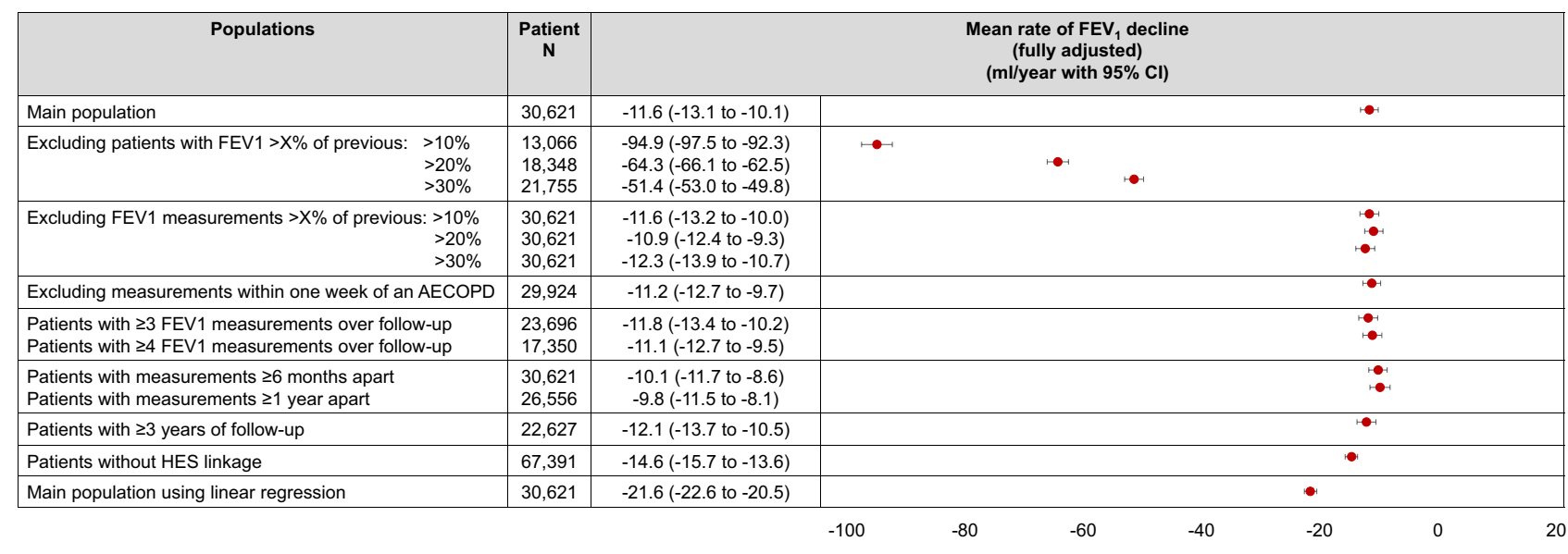

Figure 4 Fully adjusted rates of FEV, decline.

Note: Adjusted for all baseline covariates.

of consistent recording of BMI and mMRC. Fully adjusted analyses produced slower mean rates of $\mathrm{FEV}_{1}$ decline compared to crude or minimally adjusted rates of decline. However, in the population that excluded patients due to potential measurement error (population two), fully adjusted mean rates of $\mathrm{FEV}_{1}$ decline were faster than crude and minimally adjusted models. Patient populations that excluded patients with potential measurement error and who had complete baseline data included slightly milder patients than the same population regardless of complete baseline data (data not shown). On the other hand, all other patient populations who had complete baseline data had slightly more severe patients than the same populations regardless of complete baseline data. This is consistent with the theory that milder COPD patients might have faster rates of $\mathrm{FEV}_{1}$ decline due to initial lung function. ${ }^{14}$ Therefore, it is possible that missing baseline variables could influence the type of patients included in a study, and the rate of $\mathrm{FEV}_{1}$ decline.

Lastly, simple linear regression provided estimates that were slightly faster than those using mixed linear regression. Previous studies have used linear regression to describe the rate of $\mathrm{FEV}_{1}$ decline., ${ }^{4,9,17}$ The limitation to this model is that within and between patient variations are not taken into consideration by the model. If similar types of patients are included and $\mathrm{FEV}_{1}$ is not highly variable within or between patients, then linear regression can be sufficient. However, due to the nature of CPRD, a routinely collected EHR, a wide variety of phenotypes can exist, and measurement error is possible therefore, mixed linear regression should be used to take into account $\mathrm{FEV}_{1}$ variation. 
Previous studies (notably RCTs) have also estimated changes in $\mathrm{FEV}_{1}$ using two $\mathrm{FEV}_{1}$ measurements, one at baseline and one at follow-up. ${ }^{18,19}$ The nature of RCTs ensures that patients are similar in all arms of the trial and confounding is adjusted for by the study design. However, in CPRD, and other EHRs, this method could be easily biased by measurement errors, changes in maintenance therapies during follow-up, AECOPD events during follow-up, and other everyday primary care factors. This method for estimating changes in $\mathrm{FEV}_{1}$ would require the two measurements to be accurate and not be recorded close to events that may influence $\mathrm{FEV}_{1}$ such as AECOPDs and changes in medication. Overall, in order to use as much data as possible over follow-up, and to consider varying changes in individual patient decline and initial lung function, mixed linear regression should be used when studying FEV $_{1}$ using EHR.

One important limitation to acknowledge in this study is that whilst the majority (96.5\%) of spirometry measurements recorded in CPRD-GOLD are of adequate quality, pre, and post-FEV $V_{1}$ cannot always be distinguished. However, in a previous validation study of spirometry measurements in CRPD-GOLD, of those that could be distinguished, the majority of measurements were postbronchodilator spirometry. ${ }^{6}$

Overall, this study aimed to explore different definitions around longitudinal change in $\mathrm{FEV}_{1}$ in CPRDGOLD and describe differences in populations created using these definitions. Previous studies have investigated how patient characteristics are associated with $\mathrm{FEV}_{1}$ decline; however, the purpose of this study was to primarily show how mean rates of $\mathrm{FEV}_{1}$ decline differed depending on the definition used. ${ }^{8-10,20,21}$ We found that in the cohorts that did not exclude measurements or individuals due to increases in $\mathrm{FEV}_{1}$, the mean rates of $\mathrm{FEV}_{1}$ and within patient variation remained similar. For this reason, the definition used to create population one (i.e., using all available $\mathrm{FEV}_{1}$ measurements over follow-up) could be used to describe the rate of $\mathrm{FEV}_{1}$ decline in a COPD population using CPRD data. However, researchers should consider their research question prior to the selection of the definition for rate of $\mathrm{FEV}_{1}$ decline.

\section{Conclusion}

Overall, the quality of $\mathrm{FEV}_{1}$ in CPRD is adequate for the purpose of studying $\mathrm{FEV}_{1}$ decline. We found that regardless of potential measurement error, number of $\mathrm{FEV}_{1}$ measurements, time intervals between measurements, follow-up period, exclusion of specific $\mathrm{FEV}_{1}$ measurements, and linkage to secondary care data, $\mathrm{FEV}_{1}$ variability and rate of $\mathrm{FEV}_{1}$ decline remain similar in a COPD population. This suggests that CPRD is a good resource for investigating the rate of $\mathrm{FEV}_{1}$ decline in epidemiological studies and pragmatic trials. However, researchers using EHR should be aware of the difference in rate of $\mathrm{FEV}_{1}$ decline and patient characteristics when excluding individuals with questionable data.

\section{Data Sharing Statement}

Data are available on request from the Clinical Practice Research Datalink (CPRD). Their provision requires the purchase of a license and our license does not permit us to make them publicly available to all. We used data from the version collected in January 2018 and have clearly specified the data selected in our Methods section. To allow identical data to be obtained by others, via the purchase of a license, we will provide the code lists on request. Licences are available from the CPRD (http://www.cprd. com): The Clinical Practice Research Datalink Group, The Medicines and Healthcare products Regulatory Agency, 10 South Colonnade, Canary Wharf, London E14 4PU.

This research was supported by the NIHR Imperial Biomedical Research Centre (BRC). The views expressed are those of the author(s) and not necessarily those of the NIHR or the Department of Health and Social Care.

\section{Ethics Approval}

The protocol for this research was approved by the Independent Scientific Advisory Committee (ISAC) for MHRA Database Research (protocol number 16_186) and the approved protocol was made available to the journal and reviewers during peer review. This study is based in part on data from the Clinical Practice Research Datalink obtained under licence from the UK Medicines and Healthcare products Regulatory Agency. The data is provided by patients and collected by the NHS as part of their care and support. The interpretation and conclusions contained in this study are those of the author/s alone. Linked pseudonymised data was provided for this study by CPRD. Data is linked by NHS Digital, the statutory trusted third party for linking data, using identifiable data held only by NHS Digital. Select general practices consent to this process at a practice level with individual patients having the right to opt-out.

This study is based in part on data from the Clinical Practice Research Datalink (CPRD) obtained under licence 
from the UK Medicines and Healthcare products Regulatory Agency. The data is provided by patients and collected by the National Health Service (NHS) as part of their care and support. The Office for National Statistics (ONS) was the provider of the ONS Data contained within the CPRD Data and maintains a Copyright (C) 2019, re-used with the permission of The Health \& Social Care Information Centre, all rights reserved. The interpretation and conclusions contained in this study are those of the authors alone.

\section{Author Contributions}

All authors made a significant contribution to the work reported, whether that is in the conception, study design, execution, acquisition of data, analysis and interpretation, or in all these areas; took part in drafting, revising or critically reviewing the article; gave final approval of the version to be published; have agreed on the journal to which the article has been submitted; and agree to be accountable for all aspects of the work.

\section{Funding}

There is no funding to report.

\section{Disclosure}

HW reports grants from GSK, AZ, and BI, outside the submitted work; SK reports grants from Medical Research Council, during the conduct of the study; personal fees from Roche Diagnostics, personal fees from DIADEM, personal fees from AstraZeneca, outside the submitted work; JQ reports grants from British Lung Foundation and personal fees from AZ, Asthma UK, BI, Bayer, GSK, MRC, and Chiesi, outside the submitted work. The authors report no other conflicts of interest in this work.

\section{References}

1. Whittaker H, Quint JK. Using routine health data for research: the devil is in the detail. Thorax. 2020;75:714-715. doi:10.1136/thoraxjnl2020-214821

2. Tantucci C, Modina D. Lung function decline in COPD. Int J Chron Obstruct Pulmon Dis. 2012;7:95-99. doi:10.2147/COPD.S27480

3. Sin DD, Anthonisen NR, Soriano JB, Agusti AG. Mortality in COPD: role of comorbidities. Eur Respir J. 2006;28(6):1245. doi:10.1183/ 09031936.00133805

4. Vestbo J, Edwards LD, Scanlon PD, et al. Changes in forced expiratory volume in 1 second over time in COPD. $N$ Engl J Med. 2011;365 (13):1184-1192. doi:10.1056/NEJMoa1105482
5. Herrett E, Gallagher AM, Bhaskaran K, et al. Data resource profile: clinical practice research datalink (CPRD). Int J Epidemiol. 2015;44 (3):827-836. doi:10.1093/ije/dyv098

6. Rothnie KJ, Chandan JS, Goss HG, Mullerova H, Quint JK. Validity and interpretation of spirometric recordings to diagnose COPD in UK primary care. Int J Chron Obstruct Pulmon Dis. 2017;12:1663-1668. doi:10.2147/COPD.S133891

7. Quint JK, Mullerova H, DiSantostefano RL, et al. Validation of chronic obstructive pulmonary disease recording in the clinical practice research datalink (CPRD-GOLD). BMJ Open. 2014;4(7): e005540. doi:10.1136/bmjopen-2014-005540

8. Whittaker HR, Pimenta JM, Jarvis DA-O, Kiddle SA-O, Quint JA-O. Characteristics associated with accelerated lung function decline in a primary care population with chronic obstructive pulmonary disease. Int J Chron Obstruct Pulmon Dis. 2020;15:3079. (11782005 (Electronic)). doi:10.2147/COPD.S278981

9. Whittaker HR, Mullerova H, Jarvis D, et al. Inhaled corticosteroids, blood eosinophils, and FEV1 decline in patients with COPD in a large UK primary health care setting. Int $J$ Chron Obstruct Pulmon Dis. 2019;14:1063-1073. doi:10.2147/COPD.S200919

10. Whittaker HR, Bloom C, Morgan A, Jarvis D, Kiddle SJ, Quint JK. Accelerated $\mathrm{FEV}_{1}$ decline and risk of cardiovascular disease and mortality in a primary care population of COPD patients. Eur Respir J. 2020;2000918. doi:10.1183/13993003.00918-2020

11. Watz H, Tetzlaff K, Magnussen H, et al. Spirometric changes during exacerbations of COPD: a post hoc analysis of the WISDOM trial. Respir Res. 2018;19(1):251. doi:10.1186/s12931-018-0944-3

12. Whittaker HR, Jarvis D, Sheikh MR, Kiddle SJ, Quint JK. Inhaled corticosteroids and FEV1 decline in chronic obstructive pulmonary disease: a systematic review. Respir Res. 2019;20(1):277. doi:10.1186/s12931-019-1249-x

13. Quanjer PH, Tammeling GJ, Cotes JE, Pedersen OF, Peslin R, Yernault JC. Lung volumes and forced ventilatory flows. Eur Respir J. 1993;6(Suppl 16):5. doi:10.1183/09041950.005s1693

14. Mannino DM, Davis KJ. Lung function decline and outcomes in an elderly population. Thorax. 2006;61(6):472-477. doi:10.1136/ thx.2005.052449

15. Tashkin DP, Li N, Kleerup EC, et al. Acute bronchodilator responses decline progressively over 4 years in patients with moderate to very severe COPD. Respir Res. 2014;15(1):102. doi:10.1186/s12931-014$0102-5$

16. Tashkin DP, Celli B, Decramer M, et al. Bronchodilator responsiveness in patients with COPD. Eur Respir J. 2008;31(4):742. doi:10.1183/09031936.00129607

17. Kim J, Yoon HI, Oh Y-M, et al. Lung function decline rates according to GOLD group in patients with chronic obstructive pulmonary disease. Int J Chron Obstruct Pulmon Dis. 2015;10:1819-1827. doi:10.2147/COPD.S87766

18. Luoto J, Pihlsgard M, Wollmer P, Elmstahl S. Relative and absolute lung function change in a general population aged 60-102 years. Eur Respir J. 2019;53(3):3. doi:10.1183/13993003.01812-2017

19. Magnussen H, Disse B, Rodriguez-Roisin R, et al. Withdrawal of inhaled glucocorticoids and exacerbations of COPD. $N$ Engl J Med. 2014;371(14):1285-1294. doi:10.1056/NEJMoa1407154

20. Donaldson GC, Seemungal TAR, Bhowmik A, Wedzicha JA. Relationship between exacerbation frequency and lung function decline in chronic obstructive pulmonary disease. Thorax. 2002;57 (10):847-852. doi:10.1136/thorax.57.10.847

21. Calverley PM, Anderson JA, Brook RD, et al. Fluticasone furoate, vilanterol and lung function decline in patients with moderate COPD and heightened cardiovascular risk. Am J Respir Crit Care Med. 2017. 


\section{Publish your work in this journal}

Pragmatic and Observational Research is an international, peerreviewed, open access journal that publishes data from studies designed to reflect more closely medical interventions in realworld clinical practice compared with classical randomized controlled

trials (RCTs). The manuscript management system is completely online and includes a very quick and fair peer-review system. Visit http://www.dovepress.com/testimonials.php to read real quotes from published authors.

Submit your manuscript here: http://www.dovepress.com/pragmatic-and-observational-research-journal 